\title{
Integrin Alpha4/Beta7
}

National Cancer Institute

\section{Source}

National Cancer Institute. Integrin Alpha4/Beta7. NCI Thesaurus. Code C121993.

Integ rin alpha4/beta7 is a protein complex comprised of a heterodimer of integrin alpha4 and integrin beta7. This complex plays a role in cell-cell adhesion, cell-matrix adhesion, lymphocyte homing and host defense mechanisms. 